\title{
Mortality Predictors in Renal Transplant Recipients with Severe Sepsis and Septic Shock
}

\section{Mônica Andrade de Carvalho ${ }^{1 *}$, Flávio Geraldo Rezende Freitas ${ }^{1,2}$, Hélio Tedesco Silva Junior ${ }^{1}$, Antônio Toneti Bafi ${ }^{1,2}$, Flávia Ribeiro Machado ${ }^{2}$, José Osmar Medina Pestana'}

1 Unidade de Transplante, Disciplina de Nefrologia, Universidade Federal de São Paulo, São Paulo, SP, Brazil, 2 Disciplina de Anestesiologia, Dor e Terapia Intensiva. Universidade Federal de São Paulo, São Paulo, SP, Brazil

\begin{abstract}
Introduction: The growing number of renal transplant recipients in a sustained immunosuppressive state is a factor that can contribute to increased incidence of sepsis. However, relatively little is known about sepsis in this population. The aim of this single-center study was to evaluate the factors associated with hospital mortality in renal transplant patients admitted to the intensive care unit (ICU) with severe sepsis and septic shock.

Methods: Patient demographics and transplant-related and ICU stay data were retrospectively collected. Multiple logistic regression was conducted to identify the independent risk factors associated with hospital mortality.

Results: A total of 190 patients were enrolled, $64.2 \%$ of whom received kidneys from deceased donors. The mean patient age was $51 \pm 13$ years (males, 115 [60.5\%]), and the median APACHE II was 20 (16-23). The majority of patients developed sepsis late after the renal transplantation (2.1 [0.6-2.3] years). The lung was the most common infection site (59.5\%). Upon ICU admission, $16.4 \%$ of the patients had $\leq 1$ systemic inflammatory response syndrome criteria. Among the patients, $61.5 \%$ presented with $\geq 2$ organ failures at admission, and $27.9 \%$ experienced septic shock within the first 24 hours of ICU admission. The overall hospital mortality rate was $38.4 \%$. In the multivariate analysis, the independent determinants of hospital mortality were male gender $(\mathrm{OR}=5.9 ; 95 \% \mathrm{Cl}, 1.7-19.6 ; \mathrm{p}=0.004)$, delta SOFA $24 \mathrm{~h}(\mathrm{OR}=1.7 ; 95 \% \mathrm{Cl}, 1.2-2.3$; $\mathrm{p}=0.001)$, mechanical ventilation $(\mathrm{OR}=30 ; 95 \% \mathrm{Cl}, 8.8-102.2 ; \mathrm{p}<0.0001)$, hematologic dysfunction $(\mathrm{OR}=6.8 ; 95 \% \mathrm{Cl}, 2.0-$ $22.6 ; \mathrm{p}=0.002)$, admission from the ward $(\mathrm{OR}=3.4 ; 95 \% \mathrm{Cl}, 1.2-9.7 ; \mathrm{p}=0.02)$ and acute kidney injury stage $3(\mathrm{OR}=5.7 ; 95 \%$ $\mathrm{Cl}, 1.9-16.6 ; \mathrm{p}=0.002)$
\end{abstract}

Conclusions: Hospital mortality in renal transplant patients with severe sepsis and septic shock was associated with male gender, admission from the wards, worse SOFA scores on the first day and the presence of hematologic dysfunction, mechanical ventilation or advanced graft dysfunction.

Citation: Carvalho MAd, Freitas FGR, Silva Junior HT, Bafi AT, Machado FR, et al. (2014) Mortality Predictors in Renal Transplant Recipients with Severe Sepsis and Septic Shock. PLoS ONE 9(11): e111610. doi:10.1371/journal.pone.0111610

Editor: Antonio De Maio, University of California, San Diego, United States of America

Received April 19, 2014; Accepted October 2, 2014; Published November 4, 2014

Copyright: (c) 2014 Carvalho et al. This is an open-access article distributed under the terms of the Creative Commons Attribution License, which permits unrestricted use, distribution, and reproduction in any medium, provided the original author and source are credited.

Data Availability: The authors confirm that, for approved reasons, some access restrictions apply to the data underlying the findings. We would like to state that all data underlying the findings in your study are available only upon request because of restrictions imposed by the local Ethics Committee. The readers may contact Mônica Carvalho (corresponding author) to request the data.

Funding: The project was supported by funding from the Coordenação de Aperfeiçoamento de Pessoal de Nível Superior (CAPES) programme and Hospital do Rim. The funders had no role in study design, data collection and analysis, decision to publish, or preparation of the manuscript

Competing Interests: The authors have declared that no competing interests exist.

* Email: mactulha@hotmail.com

\section{Introduction}

Sepsis is the leading cause of death in non-cardiac intensive care units, although there is some evidence of a decline in mortality rates, at least in developed countries [1-4]. The scenario in emerging and limited-resources countries seems to be different with higher reported rates [5,6], although low mortality rates has also been reported [7]. The incidence of sepsis is increasing over the past years and the growing number of patients living with solid organ transplants is a factor that contributes to this finding [2$4,8]$.

The most common solid organ transplant procedure worldwide is the renal transplantation. It is the treatment of choice for endstage renal disease. Compared with chronic dialysis, renal transplantation is cost-effective, offers improved quality of life and confers a progressive survival benefit $[9,10]$. The overall survival rate of kidney grafts has improved consistently during the past decades [11]. Moreover, the number of adult candidates on the waiting lists with kidney failure continues to increase [12]. Therefore, more renal transplant recipients with functioning grafts will be exposed to pathogens while in a sustained immunosuppressive state.

Because of immunosuppression, infection frequently occurs after kidney transplantation and greatly impacts patient morbidity and mortality. This explains why infection is the second leading cause of death in renal transplant recipients, following cardiovascular diseases [13]. The importance of infection as cause of death is higher in underdeveloped countries [14,15]. Surprisingly, 


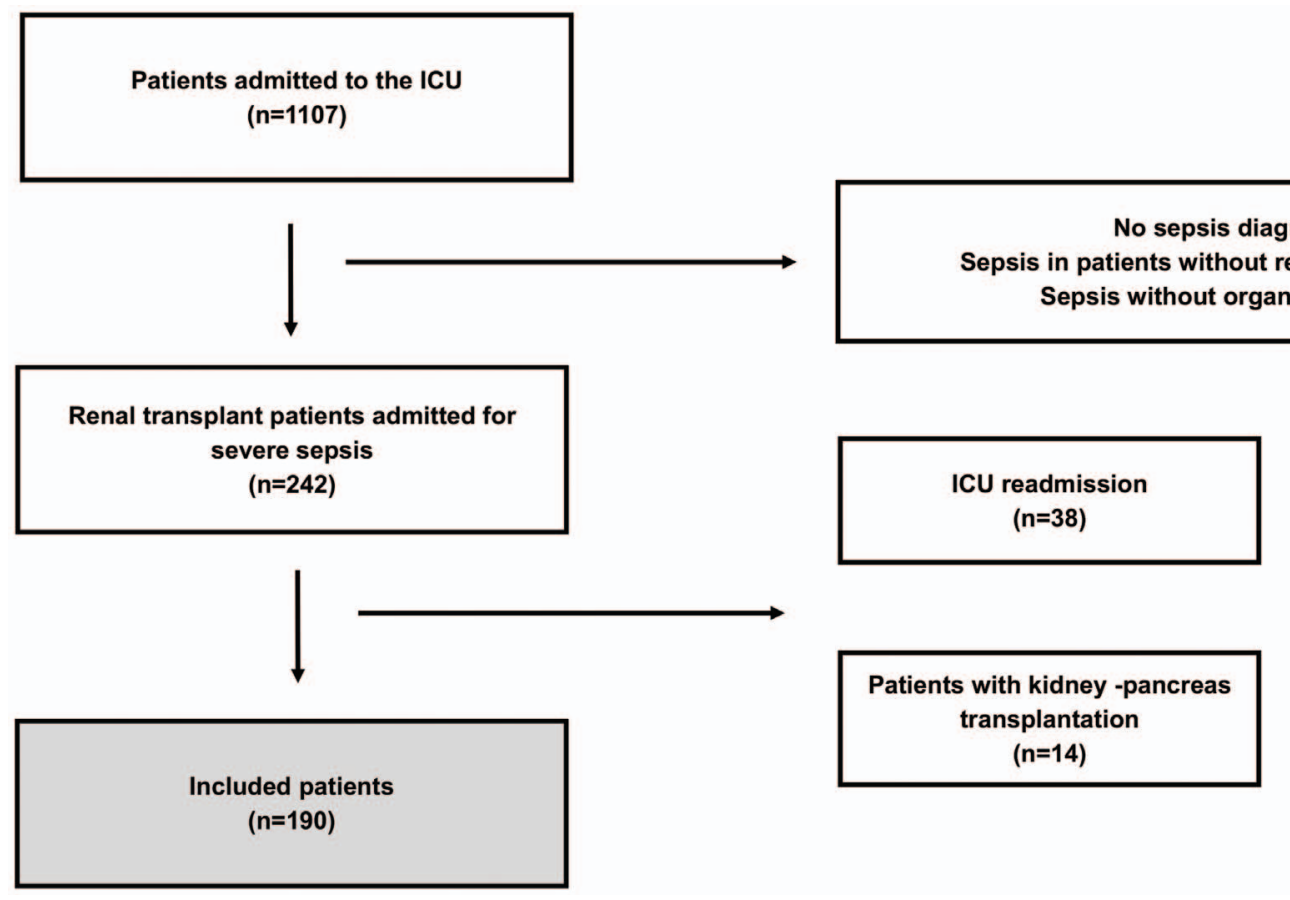

Figure 1. Study flowchart. ICU: intensive care unit. doi:10.1371/journal.pone.0111610.g001

relatively little is known about severe sepsis in this growing population. The aim of this study was to describe the characteristics of severe sepsis and septic shock in renal transplant patients who are admitted to the intensive care unit (ICU) and to evaluate the factors associated with hospital mortality.

\section{Materials and Methods}

This single center, retrospective, observational study was performed at a kidney transplant center in Brazil [16]. The institutional ethics committee approved the study and waived the informed consent requirement (Comitê de Ética em Pesquisa Universidade Federal de São Paulo, reference number: 1736-10). All consecutive adult renal transplant recipients (older than 18 years) diagnosed with severe sepsis or septic shock who were admitted to our 12-bed ICU from June 1, 2010 to December 31, 2011 were included. We excluded pregnant patients, patients who underwent kidney-pancreas transplantation, and patients with "do not resuscitate" orders. All patients were included only in their first episode of sepsis.

Data were retrospectively collected through medical records by a single author (MAC). We recorded the following data: patient demographics, comorbid chronic illnesses, severe sepsis characteristics and the severity scores Sequential Organ Failure Assessment (SOFA) and Acute Physiology and Chronic Health Evaluation II (APACHE II). We also collected data on the initial treatment, life support and fluid balance as well as pre-transplant, peritransplant and post-transplant variables. We assessed adequacy of treatment according to the compliance to the 6-hours Surviving Sepsis Campaign bundle available during the study period [17], which are similar to the recent published 3-hour and 6-hour bundles of the 2012 revised guidelines [18]. All transplant patients in our hospital are under continuous surveillance. Thus, the hospital database has all information about outpatient's visits, hospital readmissions or death in other institutions. Thus, we collected not only the hospital mortality during the septic episode but also the one-year survival. The database was reviewed by two authors (FGRF and FRM). In cases of inconsistency, the sources documents were verified, and the data were corrected. Data were anonymized and de-identified prior to data analysis.

Severe sepsis was defined as a documented or presumed infection plus at least one organ failure secondary to infection. We did not use the systemic inflammatory response syndrome (SIRS) criteria, as depressed febrile response and diminished leukocytosis are frequently seen in solid-organ recipients [19]. Septic shock was defined as volume-refractory hypotension with the need for vasopressor. Organ dysfunction was diagnosed when one of the following factors was present: hypotension with systolic blood pressure $<90 \mathrm{mmHg}$ or mean arterial blood pressure $<65 \mathrm{mmHg}$ (cardiovascular); arterial oxygen partial pressure/oxygen inspiratory fraction $\left(\mathrm{PaO}_{2} / \mathrm{FiO}_{2}\right)$ ratio $\leq 300$ (respiratory); a bilirubin level $>$ twice the reference value (hepatic); a lactate level $\geq 1.5$ times the reference value and a base deficit $>5$ (metabolic); an international normalized ratio (INR) $>1.5$ or a platelet count $<$ $100,000 / \mathrm{mL}$ (hematologic) and altered level of consciousness (neurologic). To define renal dysfunction, we used increased serum creatinine $>$ twice the baseline value. This cutoff was arbitrary chosen because of the lack of agreement on the definition of acute kidney injury (AKI) in this population. In parallel, we also used the definition recommended by Kidney Disease: Improving Global Outcomes (KDIGO) [20] to stage AKI during the ICU stay, without considering urine output.

The time to the sepsis diagnosis was defined as the number of hours elapsed between the onset of the first organ dysfunction and the recognition and management of sepsis by the healthcare provider, as described elsewhere [21]. The severe sepsis and septic shock treatment was analyzed based on compliance with the initial care bundle (within the first $6 \mathrm{hrs}$ of presentation) [22]. 
Table 1. Patient characteristics and transplant variables.

\begin{tabular}{|c|c|c|c|c|}
\hline & All Patients $(n=190)$ & Survivors $(n=117)$ & Non survivors $(n=73)$ & p value \\
\hline Age (years) & $51 \pm 13$ & $50 \pm 13$ & $52 \pm 13$ & 0.300 \\
\hline Male gender & $115(60.5)$ & $61(52.1)$ & $54(73.9)$ & 0.002 \\
\hline Body mass index $\left(\mathrm{kg} / \mathrm{m}^{2}\right)$ & $24 \pm 5$ & $25 \pm 5$ & $23 \pm 4$ & 0.003 \\
\hline \multicolumn{5}{|l|}{ Comorbidities } \\
\hline Hypertension & $152(80.0)$ & 99 (84.6) & $53(72.6)$ & 0.040 \\
\hline Diabetes mellitus & $61(32.1)$ & $39(33.3)$ & $22(30.1)$ & 0.600 \\
\hline CAD & 35 (18.4) & $24(20.5)$ & $11(15.0)$ & 0.300 \\
\hline Stroke & $8(4.2)$ & $6(5.1)$ & $2(2.7)$ & 0.700 \\
\hline $\mathrm{CHF}$ & $5(2.6)$ & $3(2.5)$ & $2(2.7)$ & 1.000 \\
\hline Hepatitis C & $13(6.8)$ & $7(5.9)$ & $6(8.2)$ & 0.500 \\
\hline Hepatitis B & $6(3.1)$ & $3(2.5)$ & $3(4.1)$ & 0.600 \\
\hline COPD & $6(3.1)$ & $1(0.8)$ & $5(6.8)$ & 0.030 \\
\hline ESRD etiology & & & & 0.220 \\
\hline Undetermined & $67(35.2)$ & $41(35.0)$ & $26(35.6)$ & \\
\hline Glomerulonephritis & $50(26.3)$ & $33(28.2)$ & $17(23.2)$ & \\
\hline Diabetes mellitus & 36 (18.9) & $18(15.3)$ & $18(24.6)$ & \\
\hline Hypertension & $28(14.7)$ & $21(17.9)$ & $7(9.5)$ & \\
\hline Urologic disease & $9(4.7)$ & $4(3.4)$ & $5(6.8)$ & \\
\hline Dialysis modality before transplant & & & & 0.480 \\
\hline Preemptive & $8(4.2)$ & $7(5.9)$ & $1(1.3)$ & \\
\hline Hemodialysis & $153(80.5)$ & $91(77.7)$ & $62(84.9)$ & \\
\hline Peritoneal & $21(11.0)$ & 14 (11.9) & $7(9.5)$ & \\
\hline Hemodialysis/peritoneal & $8(4.2)$ & $5(4.2)$ & $3(4.1)$ & \\
\hline Time of dialysis (months) & $34(18-60)$ & $32(18-60)$ & $36(24-68)$ & 0.170 \\
\hline Donor type & & & & 0.190 \\
\hline Deceased & $122(64.2)$ & $71(60.6)$ & $51(69.8)$ & \\
\hline Living & $68(35.8)$ & $46(39.4)$ & $22(30.2)$ & \\
\hline Donor gender ${ }^{a}$ & & & & 0.330 \\
\hline Female & $71(42.0)$ & $43(40.6)$ & $28(44.5)$ & \\
\hline Male & $98(58.0)$ & $63(59.4)$ & $35(55.5)$ & \\
\hline \multicolumn{5}{|l|}{ Deceased donor ${ }^{b}$} \\
\hline Cause of death ${ }^{c}$ & & & & 0.930 \\
\hline Traumatic brain injury & $33(28.0)$ & $21(30.0)$ & $12(25.0)$ & \\
\hline Subarachnoid hemorrhage & $20(16.9)$ & $12(17.1)$ & $8(16.6)$ & \\
\hline Stroke & $56(47.5)$ & $32(45.7)$ & $24(50.0)$ & \\
\hline Others & $9(7.6)$ & $5(7.2)$ & $4(8.4)$ & \\
\hline Panel reactive antibodies ${ }^{d}$ & & & & 0.660 \\
\hline $0-50 \%$ & $93(84.5)$ & $55(83.3)$ & $38(86.3)$ & \\
\hline$>51 \%$ & 17 (15.5) & $11(16.7)$ & $6(13.6)$ & \\
\hline Final creatinine ${ }^{\mathrm{e}}$ & & & & 0.210 \\
\hline$<1.5 \mathrm{mg} / \mathrm{dL}$ & 31 (32.6) & $21(35.5)$ & $10(27.7)$ & \\
\hline$\geq 1.5 \mathrm{mg} / \mathrm{dL}$ & $64(67.4)$ & $38(64.5)$ & $26(72.3)$ & \\
\hline Cold ischemia time (hours) ${ }^{f}$ & $23(20-27)$ & $23(20-28)$ & $22(20-27)$ & 0.630 \\
\hline Expanded criteria donor & $31(26.3)$ & 13 (18.6) & $18(37.5)$ & 0.020 \\
\hline Delayed graft function & $82(43.3)$ & $44(37.6)$ & $38(52.7)$ & 0.040 \\
\hline Thymoglobulin use ${ }^{\mathrm{g}}$ & $54(28.5)$ & $34(29.0)$ & $20(27.7)$ & 0.870 \\
\hline CMV disease treated & $68(35.9)$ & $41(35.0)$ & $27(37.5)$ & 0.750 \\
\hline Current immunosuppression ${ }^{\mathrm{h}}$ & & & & 0.460 \\
\hline TAC+PRED+AZA & $31(16.3)$ & $16(13.6)$ & $15(20.5)$ & \\
\hline $\mathrm{TAC}+\mathrm{PRED}+\mathrm{MF}$ & 70 (36.8) & $48(41.0)$ & $22(30.1)$ & \\
\hline
\end{tabular}


Table 1. Cont.

\begin{tabular}{|c|c|c|c|c|}
\hline & All Patients $(n=190)$ & Survivors $(n=117)$ & Non survivors $(n=73)$ & $\mathrm{p}$ value \\
\hline CSA+PRED+AZA & $17(8.9)$ & $12(10.2)$ & $5(6.8)$ & \\
\hline CSA+PRED+MF & $7(3.6)$ & $4(3.4)$ & $3(4.1)$ & \\
\hline TAC/CSA+PRED+EVR/SRL & $4(2.1)$ & $3(2.5)$ & $1(1.7)$ & \\
\hline SRL/EVR+PRED+MF & $9(4.7)$ & $4(3.4)$ & $5(6.8)$ & \\
\hline Others & $51(26.8)$ & $30(25.6)$ & $21(28.7)$ & \\
\hline Time between transplant and sepsis (years) & $2.1(0.6-7.2)$ & $2.3(0.6-7.8)$ & $1.6(0.6-7.0)$ & 0.600 \\
\hline Acute rejection & $55(28.9)$ & $34(29.0)$ & $21(28.7)$ & 0.960 \\
\hline Time rejection-sepsis (days) $^{\mathrm{i}}$ & $312(130-776)$ & $331(115-817)$ & $282(152-849)$ & 0.900 \\
\hline \multicolumn{5}{|c|}{$\begin{array}{l}\text { CAD coronary artery disease, CHF: congestive heart failure, COPD: chronic obstructive pulmonary disease, ESRD: end-stage renal disease, CMV: cytomegalovirus, TAC: } \\
\text { tacrolimus, PRED: prednisone, AZA: azathioprine, MF: mycophenolate, CSA: cyclosporine, EVR: everolimus, SRL sirolimus. } \\
\text { a) } 21 \text { missing data, } \\
\text { b) } 122 \text { deceased donors, } \\
\text { c) } 4 \text { missing data, } \\
\text { d) } 12 \text { missing data, } \\
\text { e) final creatinine refers to the donors' last serum creatinine level, } 27 \text { missing data, } \\
\text { f) } 3 \text { missing data, } \\
\text { g) patients who used thymoglobulin for treating rejection and/or induction in transplantation, } \\
\text { h) } 1 \text { missing data and i) time between the occurrence of rejection and sepsis (total of patients with rejection, } 55 \text { patients, } 3 \text { patients among the survivors and } 6 \text { among } \\
\text { the non-survivors were excluded for missing data). The results are expressed as number (\%) or median (IQR, } 25 \%-75 \%) \text { or mean } \pm \text { standard deviation. Chi-squared test, } \\
\text { Mann-Whitney U-test, and Student's t-test (univariate analysis). } \\
\text { doi:10.1371/journal.pone.0111610.t001 }\end{array}$} \\
\hline
\end{tabular}

\section{Statistical methods}

The categorical variables are described as percentages, and the continuous variables are described as measures of central tendency and dispersion, according to distribution, as assessed by the Kolmogorov-Smirnov test. We compare hospital survivors and non-survivor using the two-tailed t-test, Mann-Whitney U-test, chi-squared test, and Fisher's exact test, as appropriate. Multiple logistic regression was conducted to identify the independent risk factors associated with hospital mortality, including all variables with a $\mathrm{p}$ value $<0.10$ in the univariate analysis (using a stepwise forward regression model). The time until the sepsis diagnosis was categorized using the best cutoff value in the receiver operating characteristic (ROG) curve for mortality ( $\geq 170$ vs. $<170 \mathrm{~min}$ ). The number of organ dysfunctions $(\geq 2$ vs. $<2)$ and the KDIGO classification (stage 3 vs. stage $<3$ ) of acute kidney injury during ICU stay were also categorized. All variables were checked for confounding and collinearity. The model calibration was assessed using the Hosmer-Lemeshow test, which was considered to be appropriate if $\mathrm{p}>0.10$. We did not include the variables with missing data $>10 \%$, as the lack of data would result in serious inconsistencies. The patients were followed for one year, and a mortality curve was generated using the Kaplan-Meier methodology. A p value $<0.05$ was considered to be significant. Data were analyzed using SPSS 19.0 for Windows (SPSS, Chicago, IL, USA).

\section{Results}

During the study period, 1107 patients were admitted to the ICU, $242(21.9 \%)$ of whom were renal transplant patients who were admitted for severe sepsis. Of these patients, 190 were enrolled, as shown in Figure 1.

The patients' characteristics and transplant variables are summarized in Table 1 . The leading causes of end-stage renal disease were glomerulonephritis (26.3\%), diabetes mellitus (18.9\%) and hypertension $(14.7 \%)$, although most patients (35.2\%) did not have an identifiable cause. The majority of kidneys transplanted were from deceased donors $(64.2 \%)$. All patients had immunosuppression suspended at ICU admission and used hydrocortisone
(50 mg every six hours). The majority of the patients developed sepsis late after the renal transplantation (2.1 years; range, 0.6-2.3 years). Fifty-five patients $(28.9 \%)$ had histories of acute rejection that occurred at a median of 312 days (range, 130-776 days) before the ICU admission. The univariate analysis showed delayed graft function, and expanded criteria donor kidneys were associated with hospital mortality. No other clinical characteristic related to the transplant was significantly different between the survivors and non-survivors.

The lung was the most common site of infection (59.5\%), followed by the urinary tract $(16.8 \%)$ and abdomen $(9.5 \%)$ (Table 2). We isolated the etiologic agents in the majority of the patients $(57 \%)$. Most of these agents were bacteria (Gramnegative, 45.4\%; Gram-positive: 20.4\%). The other relevant agents were Mycobacterium tuberculosis (3.7\%), Cytomegalovirus $(3.7 \%)$ and fungi $(24 \%)$, including Pneumocystis jirovecii $(8.3 \%)$ (Table 3).

Upon ICU admission, $16.4 \%$ of the patients had $\leq 1$ SIRS criterion (Figure 2). The most common SIRS criteria were tachypnea $(74.7 \%)$ and tachycardia $(67.9 \%)$. Two or more organ failures were present at admission in $61.5 \%$ of patients. Respiratory and hematological dysfunctions occurred more frequently in the non-survivors. Fifty-three patients $(27.9 \%)$ experienced septic shock within the first 24 hours of ICU admission; however, 96 (50.5\%) patients experienced septic shock during their ICU stays. The time for severe sepsis diagnosis was longer in the non-survivors. The patients who developed sepsis in the ward had worse outcomes than those patients in the emergency room (Table 2). The compliance rate with each component of the 6-hour bundle is shown in Table 2. The compliance rate for fluid administration $(20 \mathrm{ml} / \mathrm{kg}$ crystalloid for hypotension or lactate $\geq 36 \mathrm{mg} / \mathrm{dl}$ ) was higher among the survivors.

The clinical and biological variables at the ICU admission and during the ICU stay are shown in Table 3. In the univariate analysis, most of the variables were significantly different between the survivors and non-survivors. Note that more positive fluid 
Table 2. Severe sepsis characteristics and treatment.

\begin{tabular}{|c|c|c|c|c|}
\hline & All patients $(n=190)$ & Survivors $(n=117)$ & Non-survivors $(n=73)$ & p value \\
\hline Site of infection & & & & 0.006 \\
\hline Respiratory & $113(59.5)$ & $66(56.4)$ & 47 (64.3) & \\
\hline Urinary & $32(16.8)$ & $28(23.9)$ & $4(5.4)$ & \\
\hline Abdominal & $18(9.5$ & $8(6.8)$ & $10(13.7)$ & \\
\hline Others & $27(14.2)$ & $15(12.8)$ & $12(16.4)$ & \\
\hline \multicolumn{5}{|l|}{ SIRS criteria } \\
\hline Tachypnea & $142(74.7)$ & $84(71.7)$ & $58(79.4)$ & 0.230 \\
\hline Tachycardia & $129(67.9)$ & $80(68.3)$ & $49(67.1)$ & 0.850 \\
\hline Leukocytosis & $50(26.3)$ & $28(23.9)$ & $22(30.1)$ & 0.340 \\
\hline Leukopenia & $31(16.3)$ & $16(13.6)$ & $15(20.5)$ & 0.210 \\
\hline Fever & $46(24.2)$ & $32(27.3)$ & $14(19.1)$ & 0.200 \\
\hline Hypothermia & $12(6.3)$ & $7(5.9)$ & $5(6.8)$ & 1.000 \\
\hline \multicolumn{5}{|l|}{ Organ failures } \\
\hline Respiratory & $84(44.2)$ & $43(36.7)$ & $41(56.1)$ & 0.008 \\
\hline Cardiovascular & $78(41.1)$ & $49(41.8)$ & $29(39.7)$ & 0.760 \\
\hline Renal & $77(40.5)$ & $51(43.5)$ & $26(35.6)$ & 0.270 \\
\hline Hematologic & 64 (33.9) & $30(25.6)$ & $34(46.6)$ & 0.030 \\
\hline Neurologic & $50(26.3)$ & $26(22.2)$ & $24(32.8)$ & 0.100 \\
\hline Metabolic & $13(7.9)$ & $5(4.8)$ & $8(12.9)$ & 0.070 \\
\hline Hepatic & $9(4.7)$ & $6(5.1)$ & $3(4.1)$ & 1.000 \\
\hline Admission & & & & $<0.0001$ \\
\hline Emergency & $110(57.9)$ & $83(70.9)$ & 27 (36.9) & \\
\hline Ward & $80(42.1)$ & $34(29.0)$ & $46(63.0)$ & \\
\hline Number of organs dysfunctions $(\geq 2)$ & $117(61.5)$ & $65(55.5)$ & $52(71.2)$ & 0.030 \\
\hline Glycemia $(\mathrm{mg} / \mathrm{dll})^{\mathrm{a}}$ & $149(121-194)$ & $151(121-195)$ & $141(119-193)$ & 0.360 \\
\hline Time to sepsis diagnosis (hours) & $2.5(1.1-5.2)$ & $2(0.9-4.2)$ & $3.5(1.5-6.3)$ & $<0.001$ \\
\hline Time to antibiotics (minutes) & $55(30-120)$ & $60(30-120)$ & $45(20-80)$ & $<0.001$ \\
\hline Duration of ICU stay (days) & $6(3-13)$ & $6(3-11)$ & $7(3-16)$ & 0.130 \\
\hline Duration of hospital stay (days) & $20(12-35)$ & $21(14-38)$ & $15(8-31)$ & 0.010 \\
\hline \multicolumn{5}{|l|}{ Compliance to severe sepsis bundle } \\
\hline Measure lactate & $164(86.3)$ & $103(88.0)$ & $61(83.5)$ & 0.300 \\
\hline Broad-spectrum antibiotics & $173(91.0)$ & $107(91.5)$ & $66(90.4)$ & 0.800 \\
\hline Blood cultures before antibiotics & $151(79.5)$ & $93(79.4)$ & $58(79.5)$ & 0.990 \\
\hline Fluid resuscitation ${ }^{b}$ & $54(62.3)$ & $39(75)$ & $15(44.1)$ & 0.004 \\
\hline $\mathrm{CVP}>8 \mathrm{~mm} \mathrm{Hg}^{\mathrm{c}}$ & $6(15.8)$ & $2(11.1)$ & $4(22.2)$ & 0.370 \\
\hline $\mathrm{ScvO} 2>70 \%^{\mathrm{c}}$ & $14(36.8)$ & $7(38.9)$ & $7(38.9)$ & 1.000 \\
\hline Initial care bundle & $74(39.0)$ & $45(38.5)$ & $29(39.7)$ & 0.800 \\
\hline
\end{tabular}

SIRS: systemic inflammatory response syndrome. ICU: intensive care unit. CVP: central venous pressure, $\mathrm{ScvO}_{2}$ : central venous oxygen saturation.

a) median glycemia during the first $24 \mathrm{~h}$ of sepsis,

b) indication to administer $20 \mathrm{ml} / \mathrm{kg}$ crystalloid for hypotension or lactate $\geq 36 \mathrm{mg} / \mathrm{dl}(\mathrm{n}=86)$,

c) indication to measure CVP or measure $\mathrm{ScvO}_{2}(\mathrm{n}=38)$. The results are expressed as number $(\%)$ or median (IQR: $\left.25 \%-75 \%\right)$. Chi-squared test and Mann-Whitney U-test (univariate analysis).

doi:10.1371/journal.pone.0111610.t002

balance at 72 hours was also associated with hospital mortality; however this variable was not included in multiple logistic regression due to missing data.

The basal creatinine values (before severe sepsis) were $1.93 \pm 1.44 \mathrm{mg} / \mathrm{dL}$. Four patients were under dialysis before ICU admission because of acute Kidney dysfunction. Seventy seven $(40.5 \%)$ had renal dysfunction (increased serum creatinine $>$ twice the baseline value). Staging AKI according KDIGO, 48 $(25.3 \%)$ patients reaching Stage 1, $27(14.2 \%)$ a Stage 2, and 94
$(49.5 \%)$ a Stage 3 . There was a strong association between acute kidney injury stage 3 and hospital mortality (Table 4). During ICU stay, $77(40.5 \%)$ patients underwent dialysis (conventional hemodialysis or sustained low-efficiency dialysis). The need for dialysis was higher among non-survivors $(75.3 \%$ vs. $18.8 \%, \mathrm{p}<$ $0.001)$. The need for dialysis was not included in our multivariate analysis because of its collinearity with AKI stage 3 .

The overall hospital mortality rate was $38.4 \%$ (32.1\% in severe sepsis patients and $54.7 \%$ in patients with septic shock in the first 
Table 3. Frequencies of infectious agents identified.

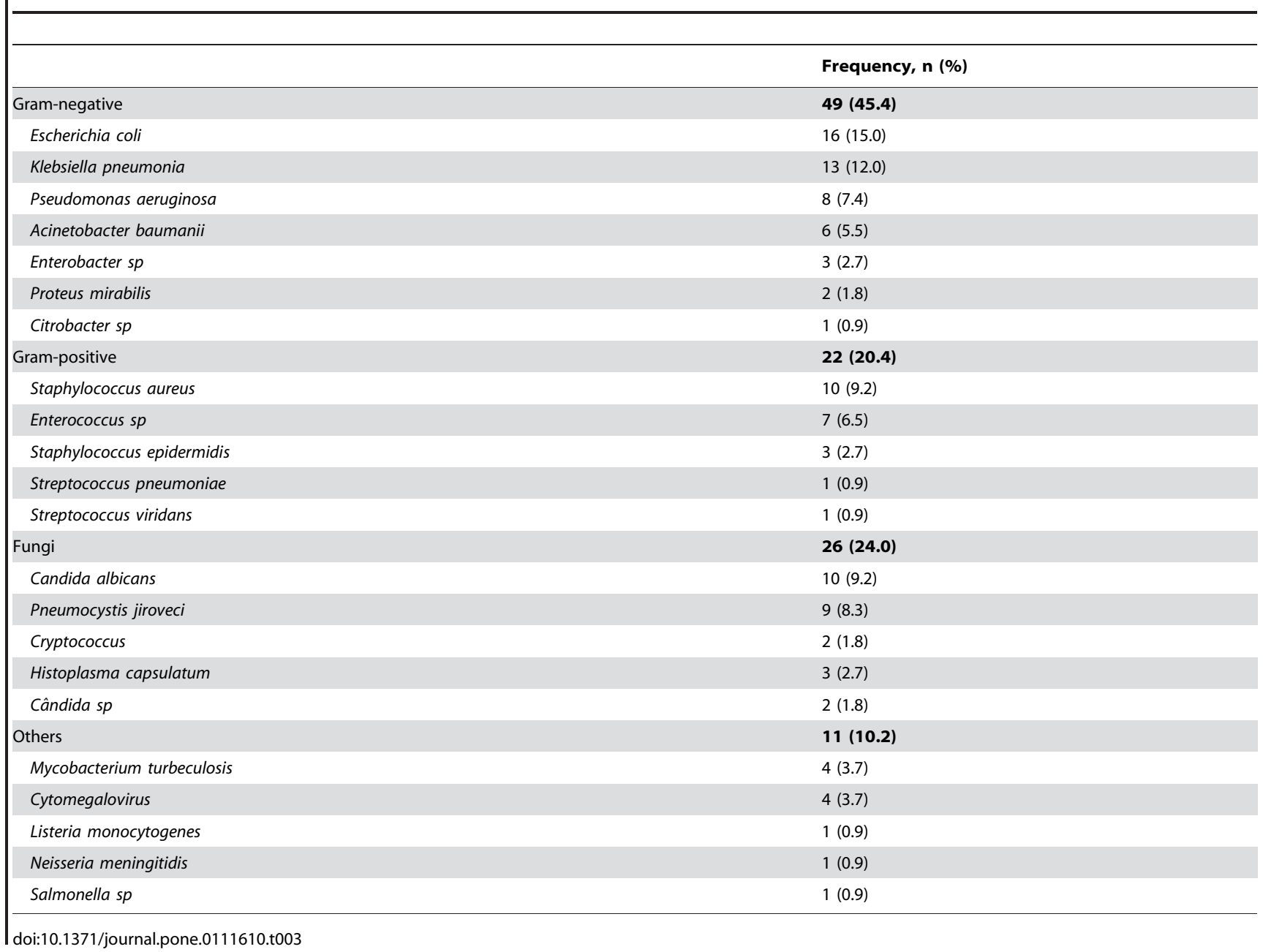

$24 \mathrm{hrs}$ of ICU admission). In the multivariate analysis, the independent determinants of hospital mortality were male gender, delta SOFA score $24 \mathrm{~h}$, mechanical ventilation, hematological dysfunction, admission from ward and AKI stage 3 (Table 5). We could assess the one-year mortality data in all patients and the rate was $42.6 \%$ (37.2\% for severe sepsis and $56.6 \%$ for septic shock). Figure 3 shows the Kaplan-Meier curves for one-year survival after ICU admission.

\section{Discussion}

In our study, we were able to show that the independent risk factors for hospital mortality in renal transplant recipients with severe sepsis and septic shock admitted to ICU did not include the transplant characteristics. There was a lower incidence of SIRS criteria than previously described in other sepsis studies, and there was a higher frequency of opportunistic pathogens causing severe sepsis. We also demonstrated a low increment in the mortality rate one-year after discharge.

The hospital mortality rate for ICU renal transplant recipients varies greatly in the literature, and no study has specifically evaluated septic patients [23-29]. Old Brazilian sepsis data from private and public ICU have shown higher mortality rates than in the present study $[21,30]$. More recent data still shows a higher mortality rate in Brazil [5] than that reported in some studies conducted in developed countries [2-4]. There are some possible explanations for this worst performance. In emerging countries, there are roughly enough resources but there is still limitation in access of care both in private and in public health systems. Sepsis awareness among lay people is restricted which contributes to a delay in searching for care. The gap between scientific evidence and bedside and staff's lack of knowledge, a frequent challenge even in the developed nations, is probably deeper in such settings. Our better findings might be partially explained by a shorter time to sepsis diagnosis [21], which was also associated with survival in our univariate analysis. In addition, the early management of these patients, as assessed by the compliance to Surviving Sepsis Campaign 6-hours bundle [17,18], was higher than those previously described $[21,22]$. The importance of high compliance with the resuscitation bundle to reduce mortality rate was demonstrated in Brazilian private hospitals [7]. In our study, there was a significant lower compliance to fluid administration in non-survivors. Interesting, non-survivors had higher fluid balance at $72 \mathrm{~h}$. This finding suggests that fluids may be essential in the earliest phases of treatment, but late administration may be harmful.

Previous sepsis cohort studies have shown an increment in the mortality rate for sepsis patients (from 7\% to 43\%) 12 months after the initial assessment (hospital or 28-days mortality) [31]. In our study, no relevant increase in the 12-month mortality rate was observed compared to the in-hospital mortality rate $(42.6 \%$ and $38.4 \%$, respectively). This interesting and previously unreported 


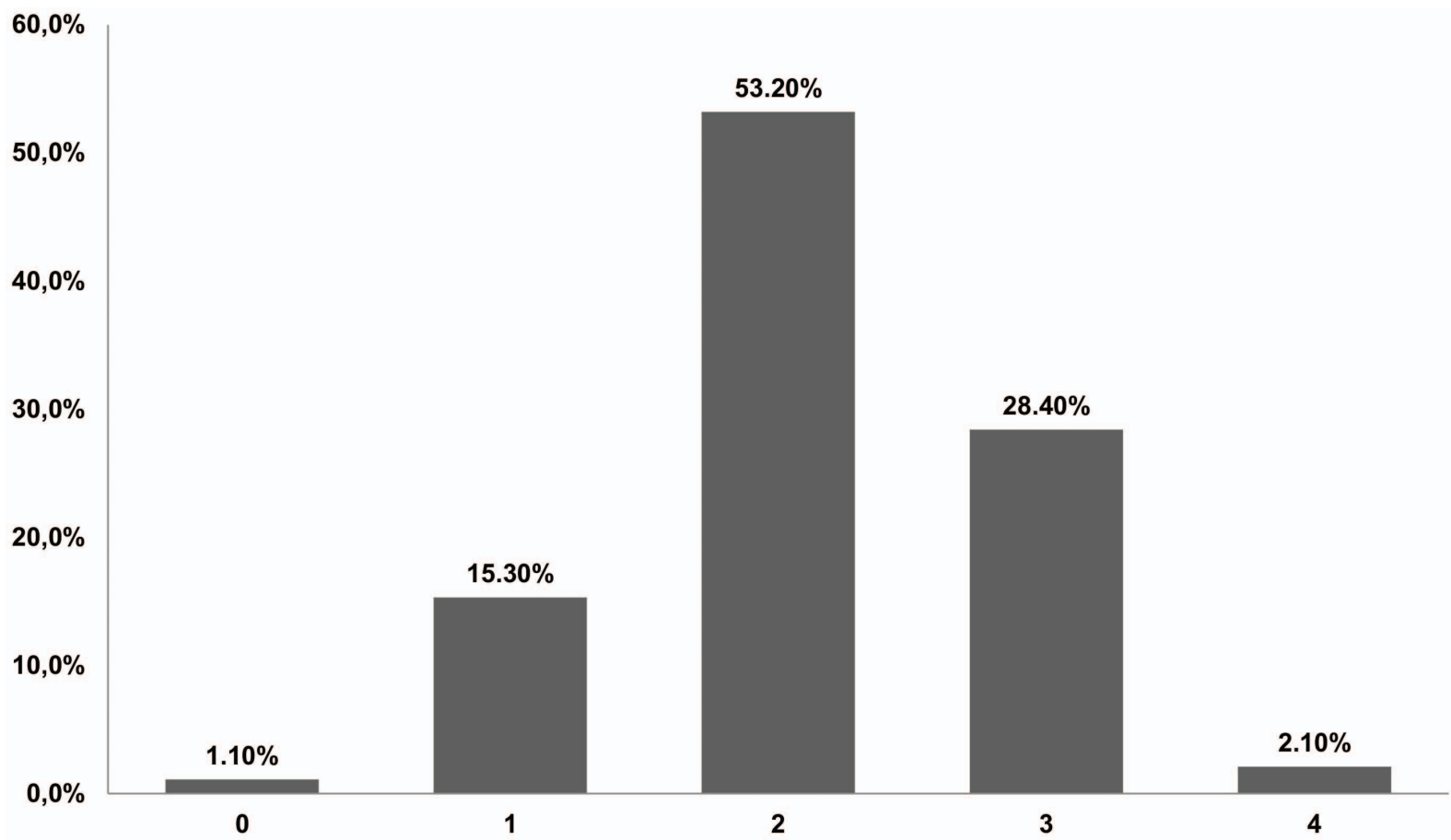

Figure 2. Frequency of systemic inflammatory response signs on intensive care unit admission. doi:10.1371/journal.pone.0111610.g002

finding might be explained, at least partially, by the fact that our patients were younger than those in other sepsis cohort studies $[1,21]$. Moreover, they were under continuous surveillance in a transplant center with adequate care during the entire follow-up period.

Considerable variations were present in our findings compared to other sepsis epidemiological studies. Our patients had fewer SIRS criteria. In a cohort, multicenter, observational study in European countries, Sprung et al. reported that approximately $90 \%$ of their septic patients had $\geq 3$ SIRS criteria, while in our study only $30 \%$ of patients had $\geq 3$ SIRS criteria [32]. Moreover, we found that $16.4 \%$ of the patients had $\leq 1$ SIRS criteria. This profile of systemic inflammatory response has been previously suggested [19,33]. Sawyer et al. demonstrated that immunosuppressed solid organ transplant patients had significantly lower maximum temperatures and white blood cells counts compared to non-transplant patients [33]. These findings should be taken into account in sepsis studies involving transplant patients, as the need for meeting SIRS criteria to define sepsis could be flawed and may not adequately reflect the actual incidence of sepsis. In fact, the current SIRS criteria to define the presence of sepsis has been criticized even in immunocompetent patients [34].

In our study, the lung was the most common site of infection, which is in alignment with other sepsis cohort studies [22,35,36]. This finding was expected, as respiratory infection is the leading cause of ICU admission and acute respiratory failure in renal transplant recipients [23,26,29,37]. The second major source of sepsis was the urinary tract. Although this is the most common infectious complication after renal transplantation [38-40], urinary infection might not lead to severe sepsis as frequently as pneumonia even in these immunosuppressed patients. Interestingly, while the data may not be significant, urinary tract infection seems to be associated with lower mortality rates, as previously showed in immunocompetent patients [41]. We also found a higher frequency of microbiologically documented infection by opportunistic pathogens compared with non-transplant patients $[1,8]$. This finding was also expected, as infections caused by opportunistic pathogens in solid organ transplant recipient are frequent [42]. However, admissions for severe sepsis did not occur during periods of intensified immunosuppression (in the first months after transplantation or after treatment for acute rejection).

Our analysis showed that the classical factors usually associated with morbidity in this population, such as immunosuppressive regimens, previous rejection treatment and CMV disease, had no prognostic value. Although delayed graft function was associated with mortality, it did not remain in our final multivariate logistic regression model. The only other variable associated with mortality in the univariate analysis, expanded criteria donor, could not be included in the model as it was assessed only in the subgroup that received a deceased-donor kidney. This result aligns with other studies in critically ill renal transplant patients requiring ICU treatment [23,25,26,29].

Delta SOFA after 24 hours of ICU admission, the need of mechanical ventilation, the presence of hematologic dysfunction and admission from the ward and not from the emergency department were previously described as mortality risk factors in critically ill general septic patients $[21,22,35,43-45]$. The most controversial risk factor found in our study was male gender. Clinical sepsis studies evaluating gender-mortality relationships are inconsistent [46-49]. Recent studies have suggested that although the incidence of sepsis is greater in men, in-hospital mortality is significantly higher among women $[48,49]$. It is possible that gender influences outcomes differently in renal transplant patients. An example of these possible interactions is the reports that grafts from male donors show a trend towards better five-year survival compared to grafts from female donors [50]. Moreover, we did not have data about hormonal concentrations. The complexity of influencing factors did not allow us to evaluate the possible pathophysiological reasons for our finding. 
Table 4. Severity scores at the ICU admission and the events during ICU stay.

\begin{tabular}{|c|c|c|c|c|}
\hline & All patients $(\mathrm{N}=190)$ & Survivors $(N=117)$ & Non survivors $(N=73)$ & p value \\
\hline SOFA admission & $5(4-8)$ & $5(4-7)$ & $6(4-9)$ & $<0.0001$ \\
\hline SOFA at $24 \mathrm{~h}$ & $5(4-8)$ & $4(3-6)$ & $7(5-11)$ & $<0.0001$ \\
\hline SOFA at $72 \mathrm{~h}$ & $5(3-8)$ & $4(2-5)$ & $8(5-11)$ & $<0.0001$ \\
\hline Delta SOFA 24 h & $0(-1-1)$ & $0(-1-0)$ & $1(0-3)$ & $<0.001$ \\
\hline Delta SOFA $72 \mathrm{~h}$ & $-0.5(-2-1)$ & $-1(-2-0)$ & $2(-0.7-4)$ & $<0.001$ \\
\hline Lactate at admission (mg/dl) & $10(7-16)$ & $10(6-16)$ & $10(7-18)$ & 0.670 \\
\hline Lactate at $6-12 \mathrm{~h}(\mathrm{mg} / \mathrm{dl})$ & $10(7-16)$ & $9(6-13)$ & $12(8-25)$ & 0.001 \\
\hline Lactate at $24 \mathrm{~h}(\mathrm{mg} / \mathrm{dl})$ & $8(6-14)$ & $8(6-10)$ & $13(7-31)$ & $<0.0001$ \\
\hline Delta lactate $6-12 \mathrm{~h}(\mathrm{mg} / \mathrm{dl})$ & $1(-3-4)$ & $0(-5-2)$ & $4(0-8)$ & $<0.001$ \\
\hline Delta lactate 24 h (mg/dl) & $0(-4-3)$ & $-2(-6-1)$ & $3(0-13)$ & $<0.001$ \\
\hline APACHE II score & $20(16-23)$ & $18(15-22)$ & $21(18-24)$ & 0.004 \\
\hline Septic shock & $53(27.9)$ & $24(20.5)$ & $29(39.7)$ & 0.004 \\
\hline Shock after $24 \mathrm{~h}$ & $96(50.5)$ & $29(24.7)$ & $67(91.7)$ & 0.004 \\
\hline Mechanical ventilation & $90(47.4)$ & $25(21.3)$ & $65(89.0)$ & $<0.0001$ \\
\hline Hemodialysis & $77(40.5)$ & $22(18.8)$ & $55(75.3)$ & $<0.001$ \\
\hline AKI classification & & & & $<0.0001$ \\
\hline Stage $<3$ & $96(50.5)$ & $80(68.4)$ & $16(21.9)$ & \\
\hline Stage 3 & $94(49.5)$ & 37 (31.6) & $57(78.1)$ & \\
\hline Reinfection in ICU & 34 (17.9) & $18(15.3)$ & $16(21.9)$ & 0.200 \\
\hline \multicolumn{5}{|l|}{ Cumulative fluid balance } \\
\hline First $6 \mathrm{~h}$ after severe sepsis ${ }^{\mathrm{a}}$ & $500(0-1500)$ & $610(0-1500)$ & $250(0-1500)$ & 0.080 \\
\hline First $12 \mathrm{~h}$ after severe sepsis ${ }^{\mathrm{b}}$ & $1500(510-2640)$ & $1500(565-2569)$ & $1175(385-2736)$ & 0.350 \\
\hline First $72 \mathrm{~h}$ after severe sepsis ${ }^{\mathrm{c}}$ & 4634 (3192-6959) & 4301 (3163-6208) & 6099 (3657-8391) & 0.007 \\
\hline First $6 \mathrm{~h}$ after septic shock ${ }^{\mathrm{d}}$ & 1500 (774-2069) & $1500(790-2000)$ & $1608(750-2678)$ & 0.710 \\
\hline First $12 \mathrm{~h}$ after septic shock ${ }^{\mathrm{e}}$ & $2190(1609-3231)$ & $2000(1394-3036)$ & $2428(1820-3330)$ & 0.350 \\
\hline First 72 h after septic shock ${ }^{f}$ & $6928(4598-8926)$ & $5460(2096-7117)$ & 8750 (6928-13162) & 0.001 \\
\hline \multicolumn{5}{|c|}{$\begin{array}{l}\text { SOFA: Sequential Organ Failure Assessment score, APACHE II: Acute Physiological and Chronic Health Evaluation II score, AKI: acute kidney } \\
\text { intensive care unit. } \\
\text { a) } n=189 \\
\text { b) } n=188 \\
\text { c) } n=153 \\
\text { d) } n=50 \\
\text { e) } n=46 \\
\text { f) } n=34 \text {. Results are expressed as number (\%) or median (IQR: } 25 \%-75 \%) \text {. Chi-squared test and Mann Whitney U-test (univariate analysis). } \\
\text { doi: } 10.1371 \text { journal.pone.0111610.t004 }\end{array}$} \\
\hline
\end{tabular}

The degree of renal allograft dysfunction during ICU stay was also associated with hospital mortality. As there is no validated classification for AKI in renal transplant recipients, we used a KDIGO definition during the ICU stays [20]. Our results demonstrated that changes in graft function are important and associated with significant changes in outcomes. This result aligns with studies using RIFLE/AKIN definitions in which a worse RIFLE or AKIN class is associated with higher mortality and

Table 5. Multivariate logistic regression analysis in septic transplant patients with hospital mortality as dependent factor.

\begin{tabular}{lll}
\hline & & OR (95\% Cl) \\
\hline Male gender & $5.9(1.7-19.6)$ & p value \\
Delta SOFA 24 h (per point increase) & $1.7(1.2-2.3)$ \\
Mechanical ventilation & $30.0(8.8-102.2)$ \\
Hematological dysfunction & $6.8(2.0-22.6)$ \\
Sepsis admitted from ward & $3.4(1.2-9.7)$ \\
AKI stage 3 & $5.7(1.9-16.6)$
\end{tabular}

OR: odds ratio, Cl: confidence interval, SOFA: Sequential Organ Failure Assessment, AKI stage 3: acute kidney injury stage 3.

doi:10.1371/journal.pone.0111610.t005 


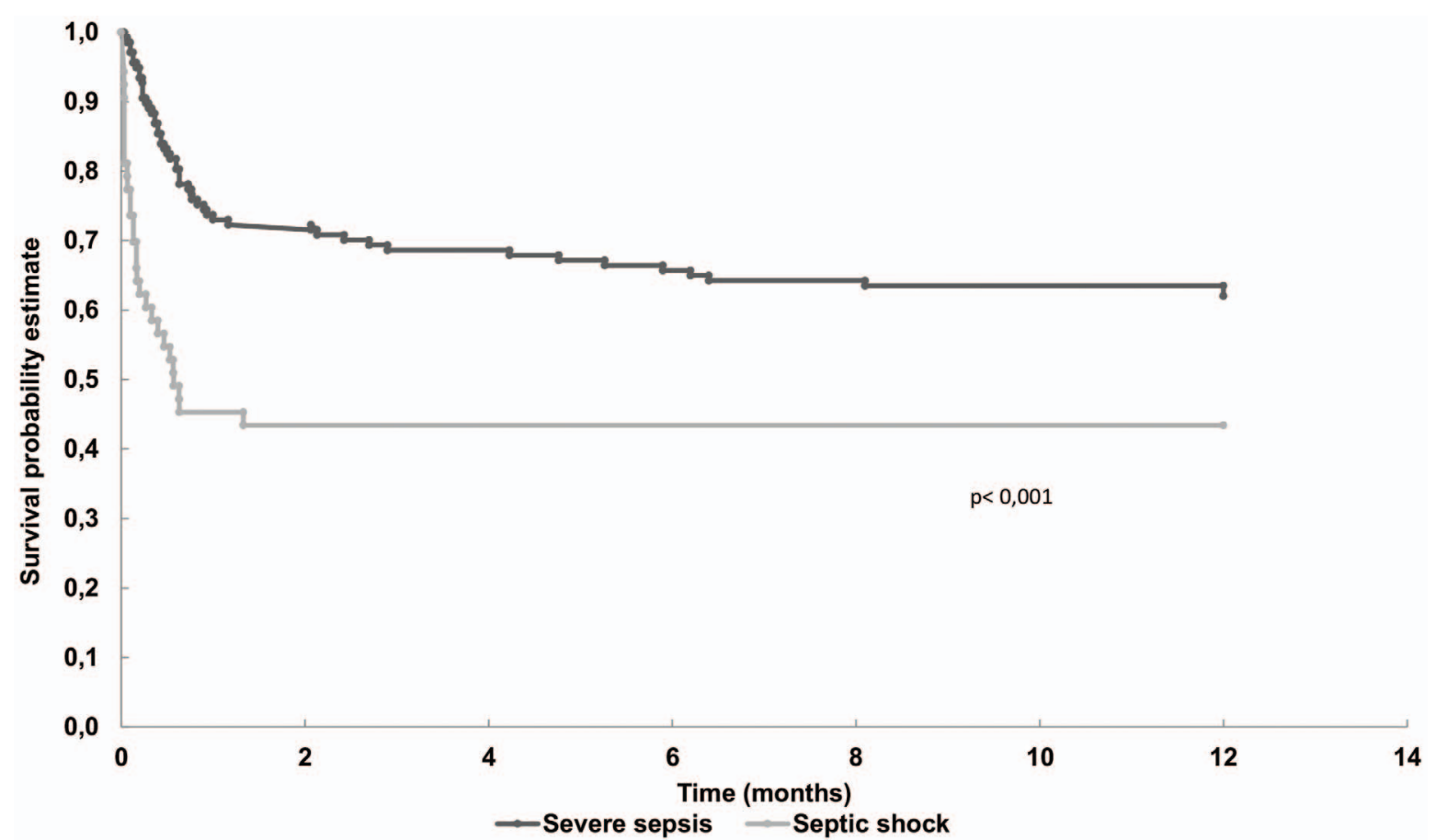

Figure 3. Kaplan-Meier curves (severe sepsis and septic shock) for one year survival after admission to the intensive care unit. doi:10.1371/journal.pone.0111610.g003

longer ICU or hospital stay [20]. This study is the first in renal transplant recipients to use a new approach of AKI classification to associate the degree of renal dysfunction with mortality. A previously reported by Nakamura et al., higher acute kidney injury states correlate with lower graft survival rates. However, the authors did not present mortality as an outcome [51].

Our study had strengths and limitations. We included a homogeneous population of renal transplant recipients in a consecutive fashion. We assessed several transplant and sepsis characteristics, including treatment adequacy, which could interfere with patient outcomes. In addition, we used a new AKI classification approach. These contributions are relevant considering the paucity of data currently available in the literature. The study also has some limitations, the most important being the retrospective nature of our data collection. Second, our study has a single-center design, which limits the reproducibility of our findings. Third, we did not have a control group with septic non-transplanted patients and transplanted patients without sepsis. Fourth, we limited our analysis to ICU patients and did not include patients with severe sepsis in other hospital settings. The relevance of this limitation should have been minimized because in this institution, the vast majority of the septic patients are admitted to the ICU. Fifth, a better characterization of AKI is lacking. We do not have data regarding estimated glomerular filtration rate, time for dialysis onset or its duration, and long-term graft function. Moreover, we did not assess the role that acute rejection could have played in graft dysfunction. We also only consider creatinine and not diuresis in our AKI classification, which may have underestimated the number of patients with late stage diseases.
However, controversy exists regarding the impact of this assessment in the score ability to predict prognosis [52]. Sixth, we have no data regarding adrenal insufficiency in our study. Besides the possibility of corticosteroid insufficiency related to critical illness or sepsis, previous chronic use of prednisone in nearly all patients could suppress the hypothalamic-pituitaryadrenal axis (HPA). This was the main reason for hydrocortisone administration. Another reason was the need for immunosuppressant drugs to prevent rejection, since all other immunosuppressant agents were discontinued at ICU admission.

\section{Conclusion}

Hospital mortality in renal transplant patients with severe sepsis and septic shock was associated with male gender, admission from the wards, worse SOFA scores on the first day and the presence of hematologic dysfunction, mechanical ventilation or advanced graft dysfunction. Transplant-related variables had no prognostic value.

\section{Acknowledgments}

We thank Creusa Maria Roveri Dal Bó for support with the statistical analyses.

\section{Author Contributions}

Conceived and designed the experiments: MAC FGRF JOMP. Performed the experiments: MAC FGRF ATB. Analyzed the data: MAC FGRF HTSJ FRM. Contributed reagents/materials/analysis tools: MAC FGRF HTSJ FRM. Wrote the paper: MAC FGRF HTSJ FRM.

\section{References}

1. Angus DC, Linde-Zwirble WT, Lidicker J, Clermont G, Carcillo J, et al. (2001) Epidemiology of severe sepsis in the United States: analysis of incidence, outcome, and associated costs of care. Crit Care Med 29: 1303-1310.
2. Kaukonen KM, Bailey M, Suzuki S, Pilcher D, Bellomo R (2014) Mortality related to severe sepsis and septic shock among critically ill patients in Australia and New Zealand, 2000-2012. Jama 311: 1308-1316. 
3. Walkey AJ, Wiener RS, Lindenauer PK (2013) Utilization patterns and outcomes associated with central venous catheter in septic shock: a populationbased study. Crit Care Med 41: 1450-1457.

4. Lagu T, Rothberg MB, Shieh MS, Pekow PS, Steingrub JS, et al. (2012) Hospitalizations, costs, and outcomes of severe sepsis in the United States 2003 to 2007. Crit Care Med 40: 754-761.

5. Latin American Sepsis Institute (2014) Surviving Sepsis Campaign. Available: http://www.ilas.org.br/upfiles/fckeditor/file/Relat\%C3\%B3rio\%20Nacional\% 20fev\%202014.pdf

6. Phua J, Koh Y, Du B, Tang YQ, Divatia JV, et al. (2011) Management of severe sepsis in patients admitted to Asian intensive care units: prospective cohort study. Bmj 342: d3245.

7. Noritomi DT, Ranzani OT, Monteiro MB, Ferreira EM, Santos SR, et al. (2014) Implementation of a multifaceted sepsis education program in an emerging country setting: clinical outcomes and cost-effectiveness in a long-term follow-up study. Intensive Care Med 40: 182-191.

8. Angus DC, Pereira CA, Silva E (2006) Epidemiology of severe sepsis around the world. Endocr Metab Immune Disord Drug Targets 6: 207-212.

9. Gallon LG, Leventhal JR, Kaufman DB (2002) Pretransplant evaluation of renal transplant candidates. Semin Nephrol 22: 515-525.

10. Davis CL (2004) Evaluation of the living kidney donor: current perspectives. Am J Kidney Dis 43: 508-530.

11. Sam R, Leehey DJ (2000) Improved graft survival after renal transplantation in the United States, 1988 to 1996. N Engl J Med 342: 1837-1838.

12. Knoll G (2008) Trends in kidney transplantation over the past decade. Drugs 68 Suppl 1: 3-10.

13. Adams PL (2006) Long-term patient survival: strategies to improve overall health. Am J Kidney Dis 47: S65-85.

14. Reis MA, Costa RS, Ferraz AS (1995) Causes of death in renal transplant recipients: a study of 102 autopsies from 1968 to 1991. J R Soc Med 1995, 88(1): $24-7$.

15. Ingsathit A, Avihingsanon Y, Rattanasiri S, Premasathian N, Pongskul C, et al. (2010) Different etiologies of graft loss and death in Asian kidney transplant recipients: a report from Thai Transplant Registry. Transplant Proc 42: 40144016.

16. Medina-Pestana JO (2010) More than 1,000 kidney transplants in a single year by the "Hospital do Rim" Group in Sao Paulo - Brazil. Clin Transpl: 107-126.

17. Dellinger RP, Levy MM, Carlet JM, Bion J, Parker MM, et al. (2008) Surviving Sepsis Campaign: international guidelines for management of severe sepsis and septic shock: 2008. Intensive Care Med 34: 17-60.

18. Dellinger RP, Levy MM, Rhodes A, Annane D, Gerlach H, et al. (2013) Surviving sepsis campaign: international guidelines for management of severe sepsis and septic shock: 2012. Crit Care Med 41: 580-637.

19. Pelletier SJ, Crabtree TD, Gleason TG, Raymond DP, Oh CK, et al. (2000) Characteristics of infectious complications associated with mortality after solid organ transplantation. Clin Transplant 14: 401-408.

20. KDIGO AKI Work Group (2012) KDIGO clinical practice guideline for acute kidney injury. Kidney inter 2: 1-138.

21. Conde KA, Silva E, Silva CO, Ferreira E, Freitas FG, et al. (2013) Differences in sepsis treatment and outcomes between public and private hospitals in Brazil: a multicenter observational study. PLoS One 8: e64790.

22. Levy MM, Dellinger RP, Townsend SR, Linde-Zwirble WT, Marshall JC, et al. (2010) The Surviving Sepsis Campaign: results of an international guidelinebased performance improvement program targeting severe sepsis. Crit Care Med 38: 367-374.

23. Klouche K, Amigues L, Massanet P, Garrigue V, Delmas S, et al. (2009) Outcome of renal transplant recipients admitted to an intensive care unit: a 10year cohort study. Transplantation 87: 889-895.

24. Mouloudi E, Massa E, Georgiadou E, Iosifidis E, Katsika E, et al. (2012) Infections related to renal transplantation requiring intensive care admission: a 20-year study. Transplant Proc 44: 2721-2723.

25. Mouloudi E, Massa E, Georgiadou E, Iosifidis E, Kydona C, et al. (2012) Course and outcome of renal transplant recipients admitted to the intensive care unit: a 20-year study. Transplant Proc 44: 2718-2720.

26. Arulkumaran N, West S, Chan K, Templeton M, Taube D, et al. (2012) Longterm renal function and survival of renal transplant recipients admitted to the intensive care unit. Clin Transplant 26: E24-31.

27. Aldawood A (2007) The course and outcome of renal transplant recipients admitted to the intensive care unit at a tertiary hospital in Saudi Arabia. Saudi J Kidney Dis Transpl 18: 536-540.

28. Candan S, Pirat A, Varol G, Torgay A, Zeyneloglu P, et al. (2006) Respiratory problems in renal transplant recipients admitted to intensive care during longterm follow-up. Transplant Proc 38: 1354-1356.
29. Canet E, Osman D, Lambert J, Guitton C, Heng AE, et al. (2011) Acute respiratory failure in kidney transplant recipients: a multicenter study. Crit Care 15: R91.

30. Beale R, Reinhart K, Brunkhorst FM, Dobb G, Levy M, et al. (2009) Promoting Global Research Excellence in Severe Sepsis (PROGRESS): lessons from an international sepsis registry. Infection 37: 222-232.

31. Winters BD, Eberlein M, Leung J, Needham DM, Pronovost PJ, et al. (2010) Long-term mortality and quality of life in sepsis: a systematic review. Crit Care Med 38: 1276-1283.

32. Sprung CL, Sakr Y, Vincent JL, Le Gall JR, Reinhart K, et al. (2006) An evaluation of systemic inflammatory response syndrome signs in the Sepsis Occurrence In Acutely Ill Patients (SOAP) study. Intensive Care Med 32: 421427.

33. Sawyer RG, Crabtree TD, Gleason TG, Antevil JL, Pruett TL (1999) Impact of solid organ transplantation and immunosuppression on fever, leukocytosis, and physiologic response during bacterial and fungal infections. Clin Transplant 13: 260-265.

34. Vincent JL, Opal SM, Marshall JC, Tracey KJ (2013) Sepsis definitions: time for change. Lancet 381: 774-775.

35. Vincent JL, Sakr Y, Sprung CL, Ranieri VM, Reinhart K, et al. (2006) Sepsis in European intensive care units: results of the SOAP study. Crit Care Med 34: 344-353.

36. Alberti C, Brun-Buisson C, Burchardi H, Martin C, Goodman S, et al. (2002) Epidemiology of sepsis and infection in ICU patients from an international multicentre cohort study. Intensive Care Med 28: 108-121.

37. Veroux M, Giuffrida G, Corona D, Gagliano M, Scriffignano V, et al. (2008) Infective complications in renal allograft recipients: epidemiology and outcome. Transplant Proc 40: 1873-1876.

38. Alangaden GJ, Thyagarajan R, Gruber SA, Morawski K, Garnick J, et al. (2006) Infectious complications after kidney transplantation: current epidemiology and associated risk factors. Clin Transplant 20: 401-409.

39. Pourmand G, Pourmand M, Salem S, Mehrsai A, Taheri Mahmoudi M, et al. (2006) Posttransplant infectious complications: a prospective study on 142 kidney allograft recipients. Urol J 3: 23-31.

40. Ak O, Yildirim M, Kucuk HF, Gencer S, Demir T (2013) Infections in renal transplant patients: risk factors and infectious agents. Transplant Proc 45: 944 948.

41. Knaus WA, Sun X, Nystrom O, Wagner DP (1992) Evaluation of definitions for sepsis. Chest 101: 1656-1662.

42. Fishman JA (2007) Infection in solid-organ transplant recipients. N Engl J Med 357: 2601-2614

43. Ferreira FL, Bota DP, Bross A, Melot C, Vincent JL (2001) Serial evaluation of the SOFA score to predict outcome in critically ill patients. Jama 286: 1754 1758.

44. Moreno R, Vincent JL, Matos R, Mendonça A, Cantraine F, et al. (1999) The use of maximum SOFA score to quantify organ dysfunction/failure in intensive care. Results of a prospective, multicentre study. Working Group on Sepsis related Problems of the ESICM. Intensive Care Med 25: 686-696.

45. Dhainaut JF, Yan SB, Joyce DE, Pettila V, Basson B, et al. (2004) Treatment effects of drotrecogin alfa (activated) in patients with severe sepsis with or without overt disseminated intravascular coagulation. J Thromb Haemost 2: 1924-1933.

46. Dombrovskiy VY, Martin AA, Sunderram J, Paz HL (2007) Rapid increase in hospitalization and mortality rates for severe sepsis in the United States: a trend analysis from 1993 to 2003 . Crit Care Med 35: 1244-1250.

47. Adrie C, Azoulay E, Francais A, Clec'h C, Darques L, et al. (2007) Influence of gender on the outcome of severe sepsis: a reappraisal. Chest 132: 1786-1793.

48. Sakr Y, Elia C, Mascia L, Barberis B, Cardellino S, et al. (2013) The influence of gender on the epidemiology of and outcome from severe sepsis. Crit Care 17: R50.

49. Pietropaoli AP, Glance LG, Oakes D, Fisher SG (2010) Gender differences in mortality in patients with severe sepsis or septic shock. Gend Med 7: 422-437.

50. Glyda Glyda M, Czapiewski W, Karczewski M, Pieta R, Oko A (2011) Influence of donor and recipient gender as well as selected factors on the five-year survival of kidney graft. Pol Przegl Chir 83: 188-195.

51. Nakamura M, Seki G, Iwadoh K, Nakajima I, Fuchinoue S, et al, (2012) Acute kidney injury as defined by the RIFLE criteria is a risk factor for kidney transplant graft failure. Clin Transplant 26: 520-528.

52. Lopes JA, Jorge S (2013) Comparison of RIFLE with and without urine output criteria for acute kidney injury in critically ill patients: a task still not concluded! Crit Care 17: 408. 